Pak. J. Biotechnol. Vol. 18 (3-4) 63-68 (2021) pISSN: 1812-1837 elSSN: 2312-7791 www.pjbt.org

http://doi.org/10.34016/pjbt.2021.18.2-3.63

\title{
EFFECT OF PROPIONIC ACID AND MIXED WAX (BEE-CARNAUBA WAX) ON TOTAL MICROORGANISM AND QUALITY OF PURPLE PASSION FRUIT AT AMBIENT TEMPERATURE
}

\author{
Nguyen Thu Huyen ${ }^{*}$ and Nguyen Minh Duc \\ National Institute of Medicinal materials, Vietnam and High school Viet Duc Hanoi \\ Email": nhatduchuyen@gmail.com
}

Article received 3.12.2021 $\quad$ Revised 25.12.2021 Accepted 29.12.2021

\begin{abstract}
:
The effects of propionic acid and mixed wax (bees and carnauba wax; MW) on total microorganisms and quality of purple passion fruit at ambient temperature $25 \pm 2{ }^{\circ} \mathrm{C}$ and $70 \%-80 \%$ relative humidity were studied. The fruits were dipped in propionic acid solution at the concentrations of $0.15 \% ; 0.25 \% ; 0.35 \%(\mathrm{v} / \mathrm{v})$ and $0.2 \%$ carbendazim, then coated with MW $2.5 \%$ by hand. After drying, they were stored at $25 \pm 2{ }^{\circ} \mathrm{C}$ for 18 days. Uncoated fruits were preserved at the same temperature as control. The determination parameters were isolation and identification of microorganisms, total microorganism, percentage of fruit decay, weight loss, total soluble solids content (TSS), total sugars, titratable acidity, and ascorbic acid content; interval time was every 3 days of storage time. The results showed that identified two kinds of microorganism were Fusarium moniliforme var. subglutinans and Fusarium oxysporum Schlecht. The concentration of $0.25 \%$ propionic acid solution and MW coating could reduce the percentage of weight loss, fruit decay, and total microorganisms for 18 days of storage time. Moreover, this combination could remain chemical qualities, as TSS, total sugars, titratable acidity, ascorbic acid content in 18 days of storage time.
\end{abstract}

Keyword: purple passion fruit, propionic, bees and carnauba wax, chemical quality, total microorganism.

\section{INTRODUCTION}

The genus Passiflora L. belongs to the family Passifloraceae. They were divided into three main types: giant granadilla (Passiflora quadrangularis L.), purple passion fruit (Passiflora edulis Sims), and yellow passion fruit (Passiflora edulis $f$. Flavicarpa Deg.) (Encyclopedia of Foods, 2002). The passion fruit is round or oval in shape, and the color can be yellow, red, purple, and green. This kind of fruit have a juicy edible center composed of a large number of seeds (Morton, 1987). Fresh passion fruit is $73 \%$ of water, $22 \%$ of carbohydrates, $2 \%$ of protein and $0.7 \%$ of fat. In a 100 gram amount, fresh passion fruit supplies 97 calories, and contains $42 \%$ dietary fiber, $36 \%$ of the daily value (DV) of vitamin $\mathrm{C}, \mathrm{B}$ vitamins riboflavin $(11 \% \mathrm{DV})$ and niacin $(10 \% \mathrm{DV}), 12 \%$ iron and $10 \%$ phosphorus (USDA Nutrient Data, 2013).

Maniwara, et al., (2015) concluded that modified atmosphere packaging (MAP) with an oxygen transmission rate of $12,000 \mathrm{~cm} 3 / \mathrm{m} 2 \cdot$ day $\cdot$ atm maintained fruit quality and extension of storage life (up to 51 days) of passion fruit. Coating of fruit is able to reduce shrinkage, weight loss, transpiration; improve the appearance and the freshness; prevent mold growth and other physical damage and disease (Thirupathi et al., 2006).

Propionic acid is a naturally occurring carboxylic acid with the chemical formula $\mathrm{CH} 3 \mathrm{CH} 2-$ $\mathrm{COOH}$. It is a liquid with a pungent and unpleasant smell some-what resembling body odor. Propionic acid was equally effective in inhibiting mold growth in a laboratory assay (Carrie and Friedhelm, 1999). Propionic acid may reasonably be considered one of the most economical organic acids for field applications of those tested (Carrie and Friedhelm, 1999)

Purple passion fruit was start ripening process and losing moisture after harvest. Then wrinkled and decay fruits develop and result in quality deterioration. Storage of purple passion fruit using propionic acid and mixed wax was purposed to extend the shelf life, reduce microbial activity and fruit decay. In Vietnam, there was no much researches report about postharvest quality of passion fruit. So this study aims to evaluate the effects of propionic acid and mixed wax-based coating (bees and carnauba wax; MW) on total microorganisms and chemical quality of purple passion fruit at ambient temperature.

\section{MATERIALS AND METHODS \\ Materials:}

Fruit samples: Purple passion fruits were harvested about 100-105 days after fruit set, when the peel color turns to purple from the private orchards in Sonla, Vietnam. Fruits sorted based on uniform size, color and shape were conducted to experiments.

Chemical preparation: Propionic acid (PA) is chemical formula $\mathrm{CH} 3 \mathrm{CH} 2 \mathrm{COOH}$, product by 
MERCK. Propionic were prepared in 3 concentrate of $0.15 \%, 0.25 \%$ and $0.35 \%$ propionic acid.

The bees wax and carnauba wax (mixed wax -MW) in the ratio of $2 / 1$ were melted at $80-85^{\circ} \mathrm{C}$, then water was added to the mixture during stirring and blending (Thinh, 2013).

\section{Methods}

Purple passion fruits were dipped in solutions of $0.15 \%$ propionic acid (CT1), $0.25 \%$ propionic acid (CT2), 0.35\% propionic acid MW (CT3) (v/v) and $0.2 \%$ carbendazim $(\mathrm{w} / \mathrm{v})$ CBZ (ĐC1) (as a control (DC)) for $1 \mathrm{~min}$ and then naturally dried. After that, purple passion fruits were coated by the mixture of bees wax and carnauba wax (mixed wax -MW) $2.5 \%(\mathrm{w} / \mathrm{v})$ and laid onto trays and stored at $25 \pm 2^{\circ} \mathrm{C}$ and $\mathrm{RH} 70-80 \%$ for 18 days, and samples /analyzed at 3 day intervals; uncoated fruits were stored at the same condition as a control (DC). A completely randomized design was used for the experiment. All measurements of each treatment were the average of three replications.

Isolation and identification of microorganisms from the purple passion fruit were classified according to Katsuhiko Ando "Identification of fungi imperfecti”, (2004).

The total microorganism populations on the surface of purple passion fruit, including molds, and yeasts were analyzed according to the method of Whangchai et al., (2006), units (CFU/g).

The percentage of decayed fruits was calculated by follows: (Number of decayed fruit/total fruit) $\mathrm{x} 100$

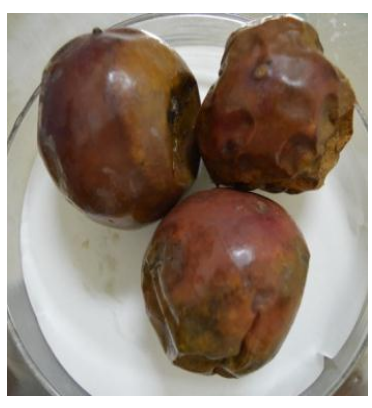

A

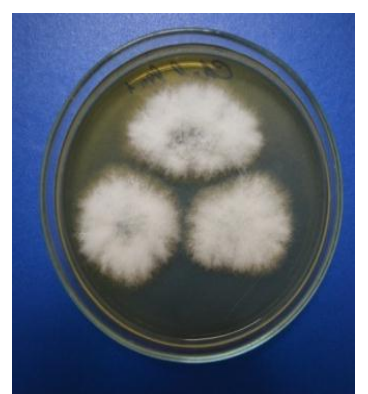

B

The percentage of weight loss was assessed as weighing the whole purple passion fruit before $(100 \%)$ and after storage. $\%$ of weight loss $=$ fruit weight (day 0) - fruit weight (day storage) x 100

The total soluble solids (TSS) content in purple passion fruit was estimated in filtered juice using a digital refractometer (RFM-80) (Atago, Tokyo, Japan)

The total sugars were determined by Lane and Eynonas described in AOAC (2000).

The purple passion fruit was analyzed for the titrable acidity (TA) as citric acid by titrating against $0.1 \mathrm{NaOH}$ by the method in AOAC (2000).

Vitamin C (ascorbic acid) was determined using the detective dye 2.6 dichlorophenolindophenol by standardizing $0.1 \%$ standard 2.6 dichlorohenolindophenol dye solution against $0.1 \%$ ascorbic acid solution according to the method described in AOAC (2000).

Statistical analysis was carried out using SPSS v.17.0 software (SPSS Inc., IL, USA). Duncan's multiple range test to analyze the significant differences $(P \leq 0.05)$ between samples.

\section{RESULTS AND DICUSSION}

Isolation and identification: Isolation and identification of post-harvest rot of purple passion fruits caused by Fusarium moniliforme var. Subglutinans Wr. \&Reink., Fusarium oxysporum Schlecht (Katsu-hiko Ando, 2004)

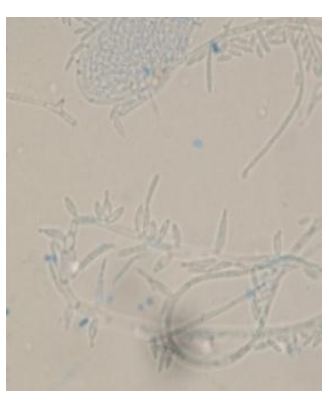

C

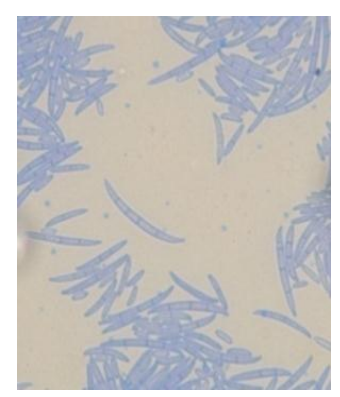

D

Fig.-1 Fusadium moniliforme var. Subglutinans Wr. \&Reink.

Fusarium moniliforme var. Subglutinans: (A) Mould on the surface of purple passion fruits; (B) Colony (MEA); (C) Head of breeding spore (x1000); (D) Spore (x1000) 


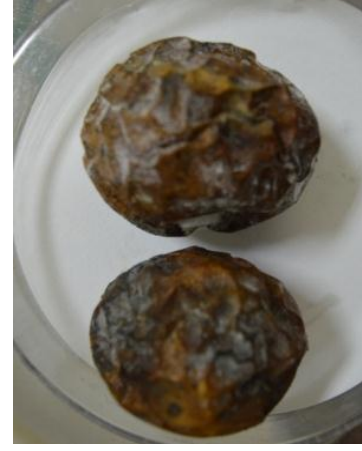

A

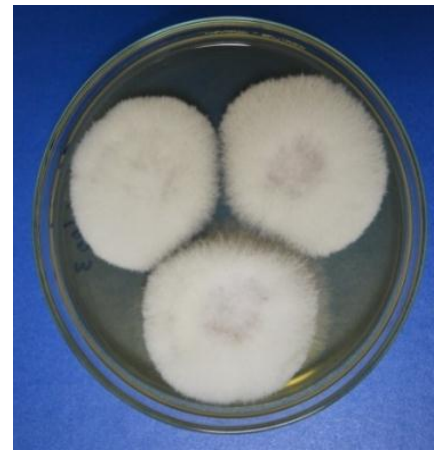

B

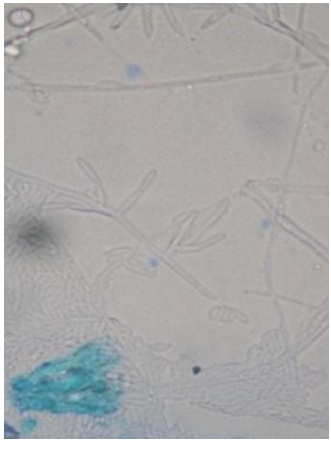

C

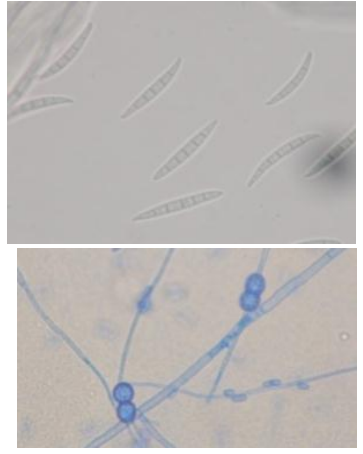

$\mathrm{D}(\mathrm{up}) \mathrm{E}($ down)

Fig.-2 Fusarium oxysporum Schlecht.

Fusarium oxysporum: (A) Mould on the surface of purple passion fruits; (B) Colony (MEA); (C) Head of breeding spore (x1000); (D) Spore (x1000); (E) Spore revealer (x1000)

In this experiment found that both $F$. moniliforme and F.oxysporum in skin of purple passion fruits. F. moniliforme and F.oxysporum are belong to Fusarium species, is a large genus of filamenttous fungi, part of a group often called to as hypohomycetes. Fusarium is widely distributed in plant, soil and ripen fruit.

Total microorganisms and fruit decay: The total microorganisms on the fruits at ambient temperature during the storage period are shown in Tab.-1. Total microorganisms of the treated and control fruits increased with increasing storage time. After 18 days in storage, the total microorganism count of CT2 was 3.0x10 $0^{4} \mathrm{CFU} / \mathrm{g}$; ĐC1 was $5.2 \times 10^{4} \mathrm{CFU}$ $/ \mathrm{g}$ and it was much lower than the control sample $\left(1.2 \times 10^{7} \mathrm{CFU} / \mathrm{g}\right)$ (Tab.1). Therefore, it suggested that propionic acid has a significant effect in inhibiting fruit decay (Fig. -3) and total microorganisms (Tab.-1). This result shows that the fruits dipped in $0.25 \%$ propionic acid solution combined with MW coating in Tab. 1 CT1, CT2 and CT3 were not different significant $(P \leq 0.05)$, can considerably prevent the increase of total microorganisms on purple passion fruit when compared with the control during 18 days storage at $25 \pm 2^{\circ} \mathrm{C}$ and RH $70-80 \%$. Total microorganisms, and decay rate (fig.-3) developed slowly at high propionic acid concentrations combined with MW at ambient temperature. Overall, there was a marked difference in total microorganisms between control and treated fruit samples after 18 days of preservation.

Tab.- 1: Effect of propionic acid and MW on total micro organisms on purple passion fruits

\begin{tabular}{|c|c|c|}
\hline Treatments & $\begin{array}{l}\text { Total micro- } \\
\text { organisms } \\
(\mathrm{CFU} / \mathrm{g}) \text { during } \\
\text { storage (0 day) }\end{array}$ & $\begin{array}{c}\text { Total micro- } \\
\text { organisms } \\
(\mathrm{CFU} / \mathrm{g}) \\
\text { during storage } \\
\text { (18 days) }\end{array}$ \\
\hline ĐC(control) & $2.6 \times 10^{6} a$ & $1.2 \times 10^{7} \mathrm{a}$ \\
\hline ĐC1 (CBZ 0.2\%) & $1.0 \times 10^{3} \mathrm{~b}$ & $5.2 \times 10^{4} \mathrm{~b}$ \\
\hline CT1 (PP 0.15\%) & $1.4 \times 10^{4} \mathrm{c}$ & $9.8 \times 10^{4} \mathrm{~b}$ \\
\hline CT2 (PP $0.25 \%)$ & $1.9 \times 10^{4} \mathrm{c}$ & $3.0 \times 10^{4} \mathrm{~b}$ \\
\hline СТ3 (PP $0.35 \%)$ & $2.9 \times 10^{3} \mathrm{~b}$ & $2.4 \times 10^{4} \mathrm{~b}$ \\
\hline
\end{tabular}

The percentage of decay fruits in the treated and control fruit during the storage period is presented in Fig. -3 at ambient temperature. The concentration of $0.15 \%, 0.25 \%$ and $0.35 \%$ propionic acid and MW was used to treat fruit have significantly reduced in decay after 18 days of storage. The decay percentage of purple passion fruit raised to $3.33 \%$ by day 18 , in case of fruits treated with $0.15 \%$ propionic acid combined with MW. There were no significant differences in fruit decay among CT2, CT3, and ĐC1. While there was significantly different among them and the control fruits $(\mathrm{P} \leq 0.05)$ after 18 days of preservation. Pulp offflavor was viewed in the fruit stored without propionic acid and MW treating fruit, and this resulted in a lack of marketability. Sang and Hai (2020) concluded that the 3 min soaking treatment in $0.2 \%$ propionic acid solution had a reduced percentage of fruit decay for 42 days in storage at $5 \pm 1{ }^{\circ} \mathrm{C}$. Bora and Narain (1997) reported that these factors contribute to the unacceptable appearance of passion fruit; this includes symptoms such as wrinkles, non-preferable color, postharvest decay and lack of nutritional content. 


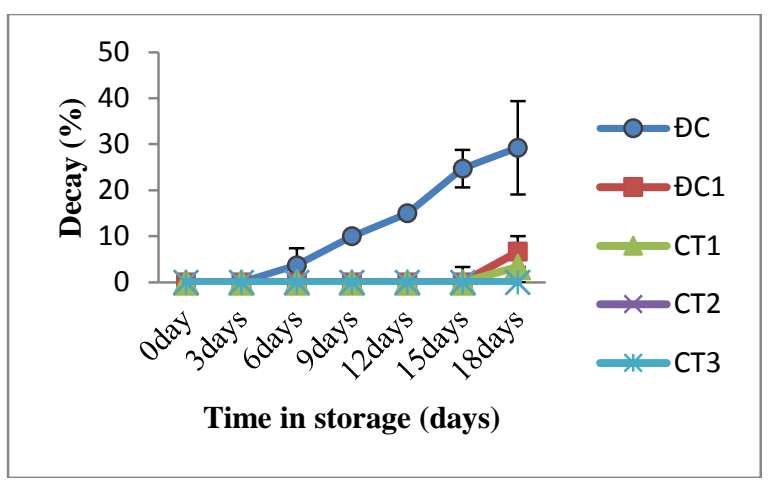

Fig.-3: The percentage of decay of purple passion fruits with propionic acid and mixed wax.

\section{Change in weight loss}

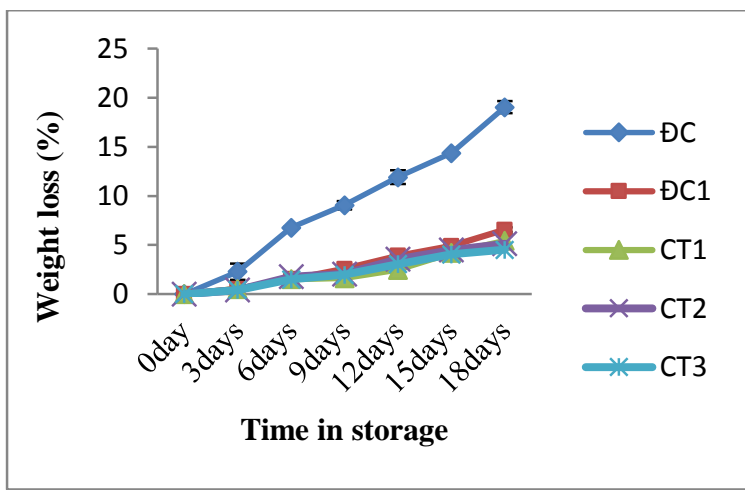

Fig.-4: Weight loss of purple passion fruits with propionic acid and mixed wax.

The percentages of weight loss of treated and control fruits during the storage period are presented in Fig.-4. After storage, purple passion fruit weight loss increased rapidly which causes reducing fruit qualities and shriveling. The weight loss was $5.14 \%$ of $0.25 \% \mathrm{PA}$ and MW treatment at the end of while this percentage of control was $29.25 \%$ at ambient temperature at 18 days of storage. There were all significantly different from the control fruit $(\mathrm{P} \leq 0.05)$ while no considerable differences in weight loss among the treated fruits $(\mathrm{P} \leq 0.05)$. This study showed that high weight loss has a relation with high decay. Chen, et al., (2016) concluded that Zixiang No.1' passion fruits using MAPs slowed down the rate of weight loss and the changes in peel defect index and other physicochemical indexes associated with passion fruit ripening and hence prolonged the shelf life of passion fruit by at least 6 days, compared to controls.

Chemical qualities: TSS, total sugars, titratable acid, vitamin $\mathbf{C}$

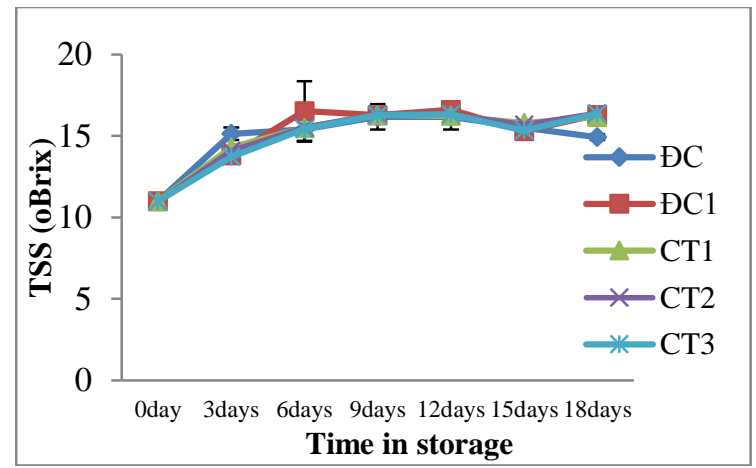

Fig.-5: TSS of purple passion fruits with propionic acid and MW

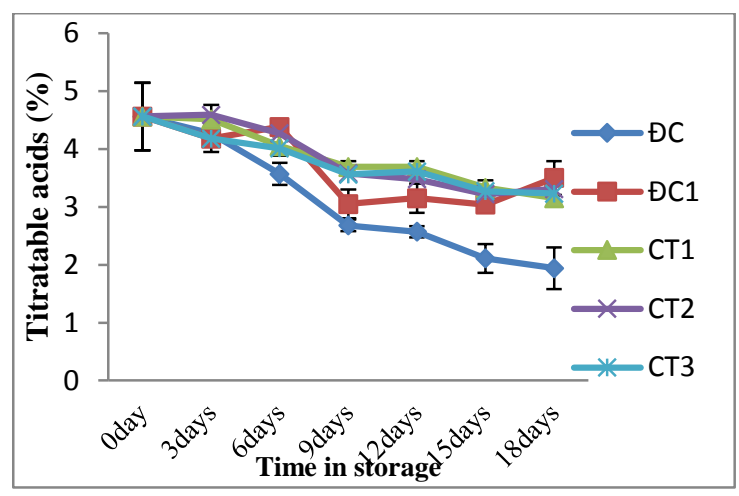

Fig.-6: Titratable acids of purple passion fruits with propionic acid and MW.

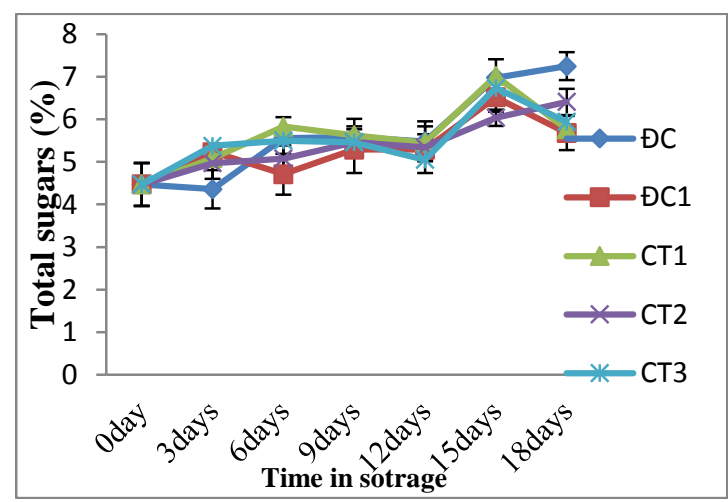

Fig.-7: Total sugar of purple passion fruits with propionic acid and MW.

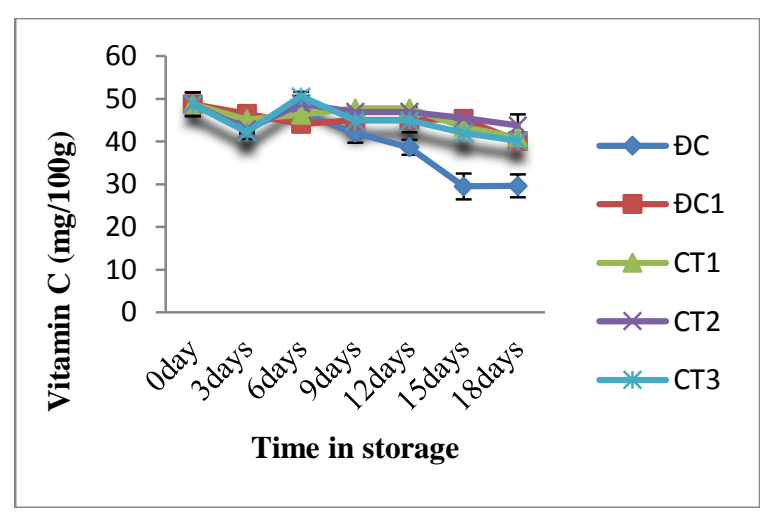

Fig.-8: Vitamim C of purple passion fruits with prpionic acid and MW. 
Fig. 5 showed that changes in TSS. The TSS increased slightly in all treatments and control. However, there was no significant difference in TSS content of propionic acid + MW treated fruits and the control fruit $(\mathrm{P} \leq 0.05)$ after 18 days of storage. The TSS of the control fruit increased from $11^{\circ}$ Brix to $16.4^{\circ}$ Brix after 18 days at ambient temperatures. Titratable acids (TA) are shown in Fig. 6. TA content of passion fruit juice decreased with storage time. The TA of the fruit treated with $0.25 \% \mathrm{PA}$ and MW and with CBZ (0.2\%) in combination with MW reduced slowly at the end of storage and not significant difference in titratable acidity has occurred in any treatments. The results are in line with the finding of Chen, et al., (2016) concluded that Zixiang No.1' passion fruits packaging was better than the ordinary one in maintaining the postharvest quality attributes of passion fruit and therefore extending its shelf life.

Changes in the total sugars are shown in Fig.-7. The total sugars of purple passion fruit increased during storage time. However, the combination of $0.25 \%$ propionic acid and MW slightly increased total sugars compared with CBZ (0.2\%) after 18 days. The increase of total sugar content was mainly due to maturation and changing titratable acids. Rong Zhang, 2019 shown that the sharpest increase of total sugar was changed PLA/PABT- and PE-packaged samples $(8.25 \%$ and $8.55 \%$, respectively) after 15 days.

The content of vitamin C (Fig.-8) was lost during the storage of purple passion fruit (one of the major organic acids enriching the juice). ĐC, ĐC1, CT1 formulas slightly delayed the loss of vitamin $\mathrm{C}$ compared with CT2, CT3 for 18 days. Vitamin C and titratable acids degradation was mainly caused by the exposure of respiration and ripeness.

Similar results were also observed by Rong et al., (2019) concluded that the weight loss, shrinkage index, firmness, and total sugar of passion fruit packaged with poly(lactic acid)/poly (butylene adipate -co-terephthalate) films had no significant differences compared with PE films during 21 days $(p>$ 0.05 ) preservation at $20^{\circ} \mathrm{C}$. Peninah et al., (2014) indicated that active bags can prolong the shelf life by maintaining quality attributes and external appearance of purple passion fruits and hence extend their marketing period. Maniwara et al., (2015) proved that the MAP-2 plastic showed the best results in maintaining fruit quality, gas composition, and extension of storage life (up to 51 days) at low temperature. Purple passion fruit soaking $3 \mathrm{~min}$ treatment in $0.2 \%$ propionic acid solution protected low total microorganism levels, low weight loss, less wrinkle on fruit pericarp, and the TSS content of the passion fruit remained unchanged at low temperature after 42 days (Sang and Hai, 2020).

\section{CONCLUSION}

Fusarium moniliforme Var. Subglutinans and Fusarium oxysporum Schlecht were isolated and identified from purple passion fruits. The fruit using $0.25 \%$ propionic acid and then coating MW inhibited the microorganism development, and the postharvest quality of fruit expressed as TSS, total sugars, vitamin $\mathrm{C}$ content and reduced the percentage of weight loss, and decay at $25 \pm 2{ }^{\circ} \mathrm{C}$ and $70 \%$ $80 \%$ relative humidity, compare with CBZ $0.2 \%$ and control after 18 days storage, favorite commercial market expressed.

Acknowledgments: The authors acknowledge funding from equipment at the laboratory of Vietnam Institute of Agricultural Engineering and Post-harvest Technology,

\section{REFERENCES}

AOAC, Official Method of Analysis, $17^{\text {th }}$ ed. AOAC International.Gaithersburg, Maryland, USA. Chapter 37: 1-7 (2000).

Bora P.S., Narain N. Passion fruit. In: Mitra S., editor. Postharvest Physiology and Storage of Tropical and Subtropical Fruits. Volume 431. CAB International; New York, NY, USA: Pp. 375-386 (1997).

Carrie H. and Friedhelm B., Efficacy of Sevevalorgnaic acids against molds, Applied Poulied Science Inc. 482-487 (1999).

ChenMeihua, Xiong Zheng, PangTingcai, Effects of Modified Atmosphere Packaging on Quality of Passion Fruit during Storage. Food science 37(20): 287-292 (2016) DOI: 10.7506/spkx 1002-6630-2016 200489

Encyclopedia of Foods (2002)

Katsuhiko Ando "Identification of fungi imperfecti" (2004).

Maniwara P., Boonyakiat D., Poonlarp P.B., Natwichai J., Nakano K. Changes of postharvest quality in passion fruit (Passifloraedulis Sims) under modifed atmosphere packaging conditions. Int. Food Res. J. 22:1596-160 (2015).

Maniwara, P., Boonyakiat, D., Poonlarp, P.B., Natwichai, J. and Nakano, K., Changes of postharvest quality in passion fruit (Passifloraedulis Sims) under modified atmosphere packaging conditions. International Food Research Journal 22(4): 1596-1606 (2015)

Morton J.F. (1987). "Passionfruit, In: Fruits of Warm Climates". NewCrop, Center for New Crops and Plant Products, Department of Horticulture and Landscape Architecture at Purdue University, W. Lafayette, IN, USA. Retrieved 22 January Pp. 320-328 (2020). 
Nutrition facts for Passion-fruit, (granadilla), purple, raw, 100 g." USDA Nutrient Data, SR-21. Conde Nast. Retrieved April 2, (2013).

PeninahYumbya, Jane Ambuko, Solomon Shibairo and Willis O. Owino, Effect of Modified Atmosphere Packaging on the Shelf Life and Postharvest Quality of Purple Passion Fruit. Journal of Postharvest Technology 2(1): 25-36 (2014)

Rong Zhang, WentingLan, Jie Ding, Saeed Ahmed, Wen Qin, Li He, and Yaowen Liu, Effect of PLA/PBAT antibacterial fiim on storage quality of passion fruit during the shelt-life. Journal molecules doi: 10.3390/molecules 24183378 (2019).

Sang N.and Hai H. L., (2020) Effect of Propionic Acid on Fruit Decay and Postharvest Quality of Vietnamese Purple Passion Fruit during Low
Temperature Storage. Acta horticulture 1312. ISHS 2021. DOI 10.17660/Actahortic.2021. 1312.66 (2021)

Thinh D.C., U.Jamnong and J. Adisak, The Suitable Coating Wax for Vietnamese Mango Fruit cv. Cat HoaLoc, $13^{\text {th }}$ ASEAN Food Conference,Singapour, 9-11 September (2013)

Thirupathi, V., Sasikala, S. and Kennedy, Z.J., Preservation of fruits and vegetables by wax coating.Retrieved May 20, 2012 from http://www. docstoc.com (2006).

Whangchai, K., K. Saengnil and J. Uthaibutra, Effect of ozone in combination with organic acids on the control of postharvest decay and pericarp browning of longan fruit. Crop Protection 25: 821-825 (2006). 